\title{
A escrita escolar a partir da Análise de Discurso: o discurso pedagógico polêmico em prol do desenvolvimento de um aluno-autor
}

\author{
Carolina Fernandes* \\ Matheus Rodrigues dos Santos**
}

\begin{abstract}
Resumo
Este artigo trata da escrita em sala de aula a partir do escopo teórico da Análise do Discurso de linha materialista, que considera a linguagem como materialidade discursiva, ou seja, produzida pela relação constitutiva do material linguístico com sua exterioridade que engloba os contextos enunciativo e sócio-histórico. Em nossas análises, investigamos a produção de autoria em três textos argumentativos produzidos por alunos de escolas públicas do Ensino Fundamental e Médio. Buscamos também observar de que forma o discurso pedagógico polêmico pode intervir na produção textual dos alunos sobre temas socioculturais, favorecendo que o sujeito-aluno se coloque na posição de autor. Comprovamos nossa hipótese de que, a partir de um discurso polêmico, estimula-se a polissemia, o que leva à criação de condições para o aluno ocupar discursivamente a posição-autor. Além disso, através dessa reflexão teórico-metodológica, discutimos sobre a abordagem de temáticas socioculturais na escola como forma de contribuir ativamente para a formação de sujeitos-cidadãos, capazes de refletir e discursivizar o mundo ao seu redor com singularidade assim como orienta a Base Nacional Comum Curricular (BNCC) de 2018 com a proposta da educação integral.
\end{abstract}

Palavras-chave: Discurso pedagógico polêmico. Autoria. Temas socioculturais.

\section{L'écriture scolaire de l'analyse du discours: le discours pédagogique polemique de l'école pour le développement d'un élève-auteur}

\section{Résumé}

Cet article s'agit de l'écriture en classe atravers le champ théorique de Analysis du Discours de ligne matérialiste qui considère le langage comme une matérialité discursive, c'est-à-dire, produite par la relation constitutive du matériau linguistique avec son externalité englobant l'énoncé et le socio-historique. Dans nos analyses, nous avons examiné la production de l'auteur dans trois textes argumentatifs produits par des élèves de primaire et de collège. Nous avons également cherché à observer comment le discours pédagogique polémique pouvait intervenir dans la production textuelle des élèves sur des sujets socioculturels, en favorisant l'étudiant en tant qu'auteur. Nous avanos confirmé notre hypothèse selon laquelle, à partir d'un discours polémique, il y a un stimulus à polysémie et, par conséquent, il existe donc des conditions pour que l'étudiant puisse occuper discursivement la position-auteur. En outre, à travers cette réflexion théorico-méthodologique, nous discutons de l'approche des questions socioculturelles à l'école comme un moyen de contribuer activement à la formation de sujets-citoyens, capables de réfléchir et de discursiver le monde qui l'entoure avec singularité comment le BNCC de 2018 avec la proposition d'éducation intégrale.

Mots-clés: Discours pédagogique polémique. Auteur. Sujets socioculturels.

Aceito: $16 / 01 / 2019$

Recebido: 12/07/2019

\footnotetext{
* Universidade Federal do Pampa (UNIPAMPA). Doutora em Letras pela Universidade Federal do Rio Grande do Sul com ênfase em Teorias do Texto e do Discurso. Professora do curso de Letras e do Curso de Mestrado Profissional em Ensino de Línguas da Universidade Federal do Pampa.

** Universidade Federal do Pampa (UNIPAMPA). Graduando do curso de Letras - Português e Literaturas de Língua Portuguesa da Universidade Federal do Pampa, campus Bagé.
} 
Neste texto, propomos uma análise da produção da escrita de textos escolares a partir do funcionamento do discurso pedagógico escolar ${ }^{1}$ (doravante DPE) polêmico (ORLANDI, 2009) com o propósito de compreender como esse tipo de discurso opera com relação à autoria na escrita dos alunos. Além disso, em uma reflexão teórico-metodológica, buscaremos atentar para a importância de o sujeito-professor abordar temáticas socioculturais na escola, pois elas permitem observar o funcionamento da língua em uso, além de corroborar ativamente para que os alunos consigam se colocar em uma posição-autor que lhes dê a oportunidade de vivenciar a polissemia para refletir e discursivizar o mundo ao seu redor com singularidade, assim como orienta a Base Nacional Comum Curricular (BNCC) (BRASIL, 2018) com a proposta da "educação integral".

Para tanto, enquanto objeto de análise, ocupar-nos-emos de textos argumentativos que registram os gestos de leitura dos alunos frente a notícias que foram relacionadas ao preconceito racial implícito em nossa sociedade. Os textos selecionados foram produzidos por alunos de terceiro ano do Ensino Médio e por um aluno de oitavo ano do Ensino Fundamental, todos oriundos da rede pública de ensino do munícipio de Bagé, no Rio Grande do Sul.

Como aporte teórico para o desenvolvimento deste trabalho, recorremos à teoria da Análise de Discurso (AD), de vertente materialista, uma vez que, para Orlandi (2009), essa vertente procura compreender a língua fazendo sentido, enquanto trabalho simbólico, parte daquilo que é social, constitutivo do homem e de sua história. Isso permite que, ao estudarmos o "discurso", seu principal objeto, possamos observar a exterioridade que o constitui, essencial, portanto, a abordagens de temas transversais, ou, como preferimos, temáticas socioculturais. ${ }^{2}$

Dessa maneira, voltamos nossa atenção para a prática docente ancorada nos conceitos de autoria e de discurso pedagógico escolar polêmico, o qual compreende um processo interpretativo polissêmico que permite aos sujeitos-alunos assumirem uma posição de autor dos seus dizeres, transpassando a noção do sujeito-enunciador, reprodutor da fala docente e ou do senso comum, para uma posição-autor em seus textos, sejam estes orais ou escritos. Para Assolini (2013, p. 44), "ocupar a posição de autor é, assim, ter direito ao exercício da palavra, quesito essencial para a formação de um sujeito-cidadão, que responde pelo seu dizer". Logo, refletir sobre os meandros que essa relação pode pressupor torna-se fundamental para o desenvolvimento de um trabalho que pense a significação de um texto e a forma como os seus sentidos podem vir a ser deslocados a partir da posição-sujeito daquele que o lê ou produz.

\section{A língua como prática social}

Na era da tecnologia digital, torna-se cada vez mais recorrente o debate acerca de qual seria a metodologia pedagógica mais adequada a fim de que os alunos passem a produzir textos marcados por autoria. Nessa conjuntura, temos defendido uma posição que enfatiza a possibilidade de o sujeitoaluno desviar-se do senso comum, bem como deslocar-se por distintos lugares interpretativos, o que só é possível de acontecer se lhes for oportunizado o contato historicizado, em sala de aula, com diferentes temáticas socioculturais. Entendemos que esse "contato historicizado" com alguma temática de cunho social e cultural significa que, além de entender as condições estritas da produção de um enunciado, o aluno consiga perceber e compreendê-las num sentido amplo, isto é, sóciohistórico, que indica toda uma rede de sentidos que cerca o discurso.

\footnotetext{
1 Especificamos o discurso pedagógico estudado aqui como sendo "escolar", visto que discursos religiosos ou mesmo o de um pai e uma mãe podem funcionar de modo pedagógico quando o propósito for o de educar/disciplinar o sujeito.

$2 \mathrm{O}$ termo se refere à sociedade e à cultura que a caracteriza; por "cultura", consideraremos, neste artigo, tal como é definida nas ciências sociais, como um conjunto de saberes (crenças, leis, moral), comportamentos, símbolos e práticas sociais, aprendidos de geração em geração, através da vida em sociedade.
} 
Para isso, é preciso refletir sobre a "língua" a partir de uma concepção que a entende enquanto prática social e histórica, resultado de processos discursivos que compreendem os movimentos parafrástico e polissêmico de significação, deixando, portanto, de ser vista como um sistema totalmente abstrato e autônomo. Pensar a língua como prática social e histórica nos faz refletir sobre as condições de leituras nas quais ela se materializa. Assim, segundo Pêcheux (2009), o sentido estrito de um texto não existe somente em si, sendo este definido pelas posições ideológicas desenvolvidas no processo sócio-histórico em que as palavras são produzidas. Frisamos que os sentidos de uma produção textual se instauram não apenas pelo que está dito/explícito, mas igualmente a partir dos não ditos que ressoam no texto. Isso ocorre porque os discursos são manipulados estrategicamente ou manifestos inconscientemente pelo sujeito-enunciador, segundo sua inscrição em determinada formação discursiva, como explica Pêcheux:

Uma palavra, uma expressão ou uma proposição não têm um sentido que lhes seja "próprio", vinculado à sua literalidade. Ao contrário, seu sentido se constitui em cada formação discursiva, nas relações que tais palavras, expressões ou proposições mantêm com outras palavras, expressões ou proposições da mesma formação discursiva. (PÊCHEUX, 2009, p. 147).

Michel Pêcheux (2009, p. 160) entende que as formações discursivas (FDs) dizem respeito àquilo que, "numa formação ideológica dada, isto é, a partir de uma posição dada numa conjuntura dada, determinada pelo estado de luta de classes, determina o que pode e deve ser dito". Essa determinação dos dizeres é histórica e ideológica, não se diz o que não se crê e não se reconhece na produção histórica do dizer. É, portanto, a partir de processos histórico-ideológicos que se constituem os discursos, assim nos é de fundamental importância, no ensino de língua portuguesa, "refletir sobre (e não a função) do efeito do-eu-aqui-agora" (ORLANDI, 2009, p. 116) na produção de dizeres e de sentidos.

Com isso, procuramos pensar as questões teórico-metodológicas a partir da vertente materialista da $\mathrm{AD}$, investigando os modos de como fazer com que os sujeitos-alunos consigam compreender e interpretar um texto e todas as especificidades que o englobam para produzir o efeito de novo em seu discurso. Afinal, diferentemente de outras teorias discursivas, na $\mathrm{AD}$, consideraremos os processos e também "as condições de produção" de um discurso. Segundo Orlandi: Podemos considerar as condições de produção em sentido estrito e temos as circunstâncias da enunciação: é o contexto imediato. E se as considerarmos em sentido amplo, as condições de produção incluem o contexto sócio-histórico, ideológico. (ORLANDI, 2007, p. 30).

Assim, para M. Pêcheux (1997), o "discurso" se faz com base em efeitos de sentido produzidos entre interlocutores, isto é, considerando o seu contexto sócio-histórico e ideológico, o enunciado significará para além do momento de sua produção. Como dito mais acima, a especificidade da AD está no fato de ela considerar a linguagem como parte indissociável da sociedade e de sua história. Orlandi (2009) considera que pensar no desenvolvimento de novos sentidos, bem como no deslocamento de outros já postos, nos permite entender o funcionamento da linguagem a partir do aspecto social no qual se constitui.

Dessa perspectiva teórica, vemos que a relação entre linguagem e exterioridade é indissociável e não complementar simplesmente, tornando, assim, as condições de produção constitutivas de todo o processo discursivo.

\section{0 sujeito discursivo e o esquecimento simbólico}

Para Michel Pêcheux (2009), a construção do sentido estabelece relação com a constituição do sujeito e vice-versa, o que torna impossível que tratemos de um sem tratarmos do outro. Os sujeitos na AD não são representados como indivíduos empíricos, mas sim correspondem "a lugares determinados 
na estrutura de uma formação social" (PÊCHEUX, 1997, p. 82), ou seja, são representações subjetivas construídas simbolicamente através de mecanismos ideológicos que determinam os sujeitos e os sentidos. Determinado assim, o sujeito não possui total consciência de si e de seus dizeres, tendo apenas a ilusão de que a possui. É constitutiva do sujeito, portanto, a ilusão de ser fonte do seu dizer, sendo condição para haver autoria.

A autoria se dá em decorrência dos dois esquecimentos simbólicos apresentados por Fuchs e Pêcheux (1997). Segundo os teóricos, o “esquecimento n 1" diz respeito ao assujeitamento ideológico que faz com que o sujeito se coloque na origem do seu dizer, como se este fosse original e único. Esse esquecimento foge ao controle do sujeito, que é levado a rejeitar e/ou apagar, de forma inconsciente, tudo o que não está inserido na FD em que se inscreve, o que lhe dá a impressão de originalidade no seu dizer. No que se refere à "ideologia", para Althusser (1992), ela deve ser encarada como algo que pode ser materializado, não estando no plano das ideias. Para ele: "O mecanismo pelo qual a ideologia leva o agente social a reconhecer o seu lugar é o mecanismo da sujeição" (ALTHUSSER, 1992, p. 8). Esse ato de sujeição se dá a partir das exigências do contexto social no qual o sujeito está inserido, que é o que faz os indivíduos ocuparem seus sempre-já-lugares nessas relações que lhes pertencem. Isso, evidentemente, não se faz apenas no plano da subjetividade, mas num conjunto de práticas e rituais que se encontram dentro de aparelhos ideológicos do estado (AIE) e em aparelhos repressores do estado (ARE) como propõe Althusser (1992).

Quanto ao "esquecimento $\mathrm{n}^{\circ} 2$ ", este se refere ao fato de o sujeito manipular a linguagem de modo a escolher a melhor forma de enunciar. Nesse processo, de modo pré-consciente, ele antecipa seu leitor, desenvolvendo estratégias de escrita, por exemplo, optando por determinados operadores argumentativos e recursos lexicais que compõem a autoria de um texto. Ele "esquece", portanto, que não tem o pleno controle sobre seu dizer, podendo o leitor se desviar dos sentidos pretendidos.

\section{A escrita na Análise do Discurso: a autoria através de temas socioculturais}

Na teoria discursiva, a escrita é abordada através da categoria de autor. Segundo a definição trazida de Foucault (1992, p. 53): “O autor é igualmente o princípio de uma certa unidade de escrita [...] $\mathrm{O}$ autor é ainda aquilo que permite ultrapassar as contradições que podem manifestar-se numa série de textos.” É um princípio de fechamento do discurso, portanto.

Assim como o sujeito discursivo não é o indivíduo de carne e osso, o conceito de autor na AD também não se confunde com o ser biológico que escreve o texto, é mais uma função do sujeito-autor, sendo essencial para estudar o texto como uma materialidade discursiva. Já que discurso é dispersão de sentidos, e, para escrever um texto, é preciso que haja uma organização dessa dispersão para produzir um efeito de unidade, eis a função da autoria, que seleciona os discursos e o modo como serão textualizados com base na memória discursiva e no modo como se posiciona com relação ao tema a ser abordado.

Se o sujeito, ao praticar a função-autor, produz clareza, progressão textual e coerência em seus dizeres, ou melhor, consistência e não contradição em seu posicionamento ideológico, ele estará desenvolvendo a autoria. Assim, todo texto possuiria uma função-autor, no entanto nem todo enunciador se coloca em uma posição-autor, ou pelo menos em uma posição que produza o efeito de originalidade e autenticidade. É o caso do "sujeito-enunciador" que designou Orlandi (2008) ou "sujeito-escrevente" como em Assolini (2011), isto é, quando o sujeito apenas enuncia o já dito, ou repete os dizeres do professor, não produzindo o efeito de novo. É comum isso acontecer quando, na sala de aula, funciona um DPE autoritário que não oportuniza ao aluno se desviar dos enunciados já legitimados pelo professor. Para Assolini (2011), o sujeito-escrevente não se coloca em uma posição 
de autor do texto que escreve porque não historiciza seu dizer, apenas reproduz o DPE. Fernandes (2017) explica como o discurso autoritário, sendo o que é tradicionalmente presente nas escolas, afeta a autoria dos alunos:

O aluno-escrevente, portanto, executa a tarefa de escrita, organiza sua produção, mas, em virtude da submissão ao discurso pedagógico escolar tradicional, deixa de produzir o efeito de autenticidade e de originalidade, passando a reproduzir os sentidos que imagina ser esperados pelo professor. (FERNANDES, 2017, p. 139).

Assim, o sujeito, buscando uma posição de bom aluno, não produz gestos singulares de interpretação, apenas a repetição do DPE e sua aprovação. Consideramos, portanto, a escrita como uma questão de produção de autoria que pode ser vista, como propõe Fernandes (2017), em termos de "graus", apontando uma escala entre a função-autor e a posição-autor.

Com relação à interpretação de textos socioculturais, é imprescindível que o sujeito-aluno se coloque em uma posição de autor, já que se espera dele uma atuação, mesmo que simbólica, na sociedade em que vive. Desde os Parâmetros Curriculares Nacionais (BRASIL, 1998), a escola toma para si o dever de formar sujeitos-cidadãos que sejam capazes de pensar, refletir e resolver problemas sociais, o que, na BNCC (BRASIL, 2018, p. 14), aparece especificado no compromisso com a "educação integral" que visa à "formação e desenvolvimento humano global". Para isso, é destacada a formação da cidadania por meio da abordagem de temas contemporâneos de relevância social, isto é, "que afetam a vida humana em escala local, regional e global” (BRASIL, 2018, p. 19). Logo, introduzir tais temas no ambiente escolar é agir ativamente no desenvolvimento do sujeito-cidadão, uma vez que somente por meio deles é possível dar visibilidade a discursos de fora do senso comum. Assim, é importante colaborarmos para que os alunos atinjam uma posição de questionamento ou deslocamento no interior das formações discursivas em que estão inscritos, ainda mais sendo o discurso a mediação entre a linguagem e o mundo.

Para Orlandi (2009, p. 15): “A mediação, que é o discurso, torna possível tanto a permanência e a continuidade quanto o deslocamento e a transformação do homem e da realidade em que ele vive. $\mathrm{O}$ trabalho simbólico do discurso está na base da existência humana."

Portanto, a adoção da AD como uma perspectiva de funcionamento da linguagem pode evidenciar que a relação entre linguagem, pensamento e mundo não é e nunca poderá ser plena, de sentido único e imutável, mas opera entre a reprodução e a transformação dos processos de significação. E entendemos que promover a polissemia, através do DPE polêmico, para que o aluno se coloque na posição de autor, é o primeiro passo.

\section{Os discursos pedagógicos escolares e o estímulo à polissemia}

No que se refere ao aspecto discursivo do ambiente escolar, refletir sobre o funcionamento do DPE enunciado pelo professor se torna relevante para pensar a relação entre os processos de ensino e aprendizagem e os sujeitos neles implicados. Orlandi (2009) mostra que o DPE funciona de modo específico por ser formulado a partir de relações de poder dentro de aparelhos de estado. Ainda que não sejam passíveis de enquadramentos, a autora (ORLANDI, 2009) sugere três tipos de DPE: o "discurso autoritário", em que se tem como intuito conter a reversibilidade, tentando diminuir ao máximo a aparição da polissemia em aula; o "discurso polêmico", em que existe certo equilíbrio na forte relação entre a polissemia e a paráfrase, com a reversibilidade se dando sob certas condições; e o "discurso lúdico", em que se tende para a polissemia total. Ainda com Orlandi (2009), pode-se dizer que o exagero do discurso autoritário é a ordem no sentido militar, o do polêmico, é a injúria, e o exagero do lúdico é o non-sense. 
Observamos, juntamente com Orlandi (2009), que o DPE, da forma como funciona nas escolas brasileiras, é predominantemente autoritário, visto que tem sua manifestação muito mais voltada para a paráfrase discursiva do que para a polissemia, o que evita a reversibilidade, não dando voz ao aluno.

O discurso autoritário não se limita ao ambiente escolar, mas se manifesta toda vez que há interdições ao dizer, em espaços públicos de discussões, impedindo a resistência. O autoritarismo aparece normalmente nas faces de um discurso do poder (ORLANDI, 2009), o qual se materializa por meio de um sistema punitivo que, ao pautar-se no certo e no errado, gerará, como no caso da escola, o sentimento de fracasso no aluno. Para a autora (ORLANDI, 2009), o tipo autoritário é um discurso que funciona por meio de uma relação pautada exclusivamente na transmissão de informações, ou seja, o aluno só reproduz o conhecimento, não participando de sua produção.

Segundo Orlandi (2009), superar esse discurso seria transformá-lo numa espécie de discurso polêmico, em que o pensamento crítico seja estimulado através de questões abertas para que os alunos consigam compreender o funcionamento da linguagem na produção de sentidos. Para tanto, o sujeitoprofessor teria de, através da interação com o aluno, deslocar-se de sua posição privilegiada de fala para outra que passasse mais a ouvir, explorando ao máximo os temas socioculturais debatidos em sala de aula, conforme indica a proposta de Orlandi para o DPE polêmico. Assim, para a autora: "ser crítico, tanto pelo lado do locutor quanto do ouvinte, é questionar as condições de produção desses discursos. Nessas condições de produção, é determinante a presença e função da escola, que é o lugar próprio do discurso pedagógico.” (ORLANDI, 2009, p. 86).

Dessa maneira, romper, mesmo que parcialmente, com o caráter autoritário do DPE, rumando para um discurso polêmico, se faz necessário para a formação de uma sociedade democrática composta por cidadãos críticos e conscientes de suas responsabilidades. A proposta da autora (ORLANDI, 2009) para o ensino é, portanto, fazer predominar o DPE polêmico, pois, além de ele propiciar a prática da polissemia, que favorece a autoria dos alunos, possibilita, também, um diálogo entre a escola e as temáticas de cunho social, agindo como uma forma de relacionar o saber estruturado ao "mundo real".

\section{Uma análise das produções textuais de alunos a partir de um DPE polêmico}

Para efetuarmos nossa análise, primeiro situaremos o contexto da intervenção pedagógica que levou à coleta de dados/fatos linguísticos; em segundo, faremos a análise dos recortes das produções textuais realizadas em aula, buscando observar de que modo o DPE polêmico favoreceu a tomada da posição-autor pelos sujeitos-alunos.

As escolas onde desenvolvemos atividades articuladas ao projeto de pesquisa Análise do Discurso e Ensino de Língua vinculam-se às redes públicas municipais e estaduais, sendo uma de Ensino Fundamental, situada na periferia da cidade, e a outra, de Ensino Médio e Técnico, situada em zona central. Para cada contexto, foi elaborado um projeto de ensino específico durante o primeiro e segundo semestres de 2018, ambos com o tema: o preconceito racial sofrido pela população negra no Brasil e os movimentos de resistência a esses discursos racistas. As atividades consistiram de leituras de textos jornalísticos, obras visuais, charges e HQs que incitaram discussões e debates em sala de aula sobre os temas abordados, em seguida produções textuais do gênero dissertativo-argumentativo, com base nas discussões realizadas em aula.

Em nossa análise, focalizaremos o recorte de três gestos de leitura possíveis para duas notícias publicadas no site UOL Notícias - "Caso Rafael Braga: Justiça nega liberdade a catador condenado por tráfico", 3 e a segunda, "CNJ analisa se desembargadora interferiu em soltura de filho pego com $129 \mathrm{~kg}$ de maconha no MS". ${ }^{4}$

3 Cf. em https://noticias.uol.com.br/cotidiano/ultimas-noticias/2017/08/08/caso-rafael-braga-justica-nega-liberdade-decatador-condenado-por-trafico.htm.

4 Cf. em https://noticias.uol.com.br/ultimas-noticias/agencia-estado/2017/07/26/cnj-analisa-se-desembargadora- 
Primeiramente, foi feita a leitura das notícias de forma individual e, em seguida, coletivamente, para que, após isso, se sucedesse um debate sobre o assunto abordado nos textos. Para motivar o debate, foram feitos alguns questionamentos, como: sobre o que as notícias tratavam; se elas tinham relação entre si; como eram retratados os sujeitos suspeitos em cada uma delas, entre outros. Destacamos ainda que buscamos direcionar o mínimo possível o debate para não interferir nos gestos de interpretações dos alunos, como propõe o DPE polêmico, já que sempre foi dado espaço para que eles se posicionassem de diferentes modos, não atribuindo suas manifestações como corretas ou inadequadas, nem valorizando algumas intervenções em detrimento de outras.

Após isso, cada aluno produziu um texto para registrar seus gestos de interpretação acerca do que fora debatido, ou seja, a opinião sobre as notícias lidas e como poderiam ser relacionadas. A partir dessa atividade escrita, pudemos perceber que foram distintos os gestos de interpretação textualizados, o que tornou visível as possibilidades de tomada de posição que os sujeitos-alunos puderam assumir e a atenção que tiveram para com a forma de composição dos textos estudados.

Ao analisarmos as duas notícias, percebemos existir uma diferença de tratamento na forma como os sujeitos suspeitos são enunciados. Afinal, já em suas manchetes, temos, de um lado, "o catador condenado por tráfico", em que lemos implicitamente "o traficante", enquanto do outro, "o filho da desembargadora, que foi pego com 129kg de maconha", é tratado como "empresário" e sem qualquer menção a tráfico ou traficante, o que já permite questionar o modo como a imprensa divulgou esses fatos.

No debate com toda a turma sobre o conteúdo das notícias, os alunos, em sua maioria, perceberam essa diferença, observando haver também uma disparidade no modo como o Judiciário brasileiro julgou cada caso. O filho da desembargadora, Breno Borges, foi liberado, em segunda instância, da acusação de tráfico, mesmo sendo pego em flagrante com $129 \mathrm{~g}$ de maconha, uma pistola 9mm e munições, enquanto que o catador Rafael Braga foi condenado a 11 anos e três meses de prisão por portar apenas 0,6g de maconha e 9,3g de cocaína. Por suas manifestações orais, notamos que, pelo fato de o condenado ser pobre e negro, os alunos produziram o efeito de injustiça e desaprovação da Justiça brasileira, o que também pudemos observar em suas produções escritas. A seguir, analisamos três produções textuais que registraram diferentes gestos de interpretação das notícias.

\section{Texto $1^{5}$}

Mídia: uma democracia real em seu olhar sobre o mundo?

A mídia em sua grande parte, tem tratado cada noticia de uma forma diferente, mesmo que sejam os mesmos tipos de casos com os mesmos tipos de ocorrência. Não sendo totalmente imparcial.

Certamente, a classe social da pessoa noticiada define a forma de como ela se encontra em uma ocorrência e até mesmo numa situação de prisão é julgada pela classe e não pelo que realmente foi cometido. O cara preto e pobre é sempre tratado diferente do rico e branco. Nesse caso, o morador de rua foi preso por tráfico portando poucas gramas de cocaína, já no outro caso em que o filho de uma desembargadora foi encontrado com mais de $100 \mathrm{~kg}$ de drogas, ele foi julgado como portador de uma doença psicológica e então liberado.

Ambas noticias tratavam do ocorrido a partir da cor da pele do individuo e da sua situação social e econômica. Me parece que a diferença de cor e de razões sociais são os fatores que definem constantemente os casos que serão divulgados ao público e de como a notícia será escrita. Acho isso complicado para aqueles que são negros. 
Nessa primeira materialidade, temos um sujeito que interpreta a prisão de Rafael Braga como uma injustiça, ressaltando o modo como a mídia retratou o caso. Logo no título de seu texto, o autor questiona: "Mídia: uma democracia real em seu olhar sobre o mundo?", permitindo-nos dois gestos interpretativos possíveis acerca dessa relação entre as palavras "mídia" e "democracia" organizadas num mesmo enunciado. O primeiro gesto indicaria que, se por um lado, existe uma "democracia real", para ele, por outro, existe uma que não cumpre com seu sentido mais recorrente, de que o povo, independentemente de raça ou classe social, teria direito a uma vida digna e às prioridades sobre as decisões de uma nação. O segundo estaria no que se refere ao questionamento sobre a democratização da mídia em nosso país, visto que esta é uma pauta bastante debatida na atualidade e que sempre volta à tona nos debates sobre o assunto.

No corpo do texto 1, o uso de advérbios de tempo é bastante marcado. Marcas como "sempre", em "o cara preto é sempre (grifo nosso) tratado diferente do rico e branco", e "constantemente", em "a diferença de cor e de razões sociais são os fatores que definem constantemente (grifo nosso) os casos que serão divulgados ao público", sugerem que, na interpretação do sujeito-aluno, tais formas de injustiça não são fatos isolados, mas recorrentes em nossa sociedade.

A maneira como o aluno inscreve suas visões de mundo tem relação direta com a forma pela qual ele é interpelado ideologicamente. Isso produz um efeito de indignação por meio daquilo que está enunciando, como quando mais de uma vez dá a entender que os fatores social e de raça são predominantes para a maneira como o julgamento e as notícias se desenvolvem, o que indica que, na FD que determina seu discurso, isso não é entendido como correto ou justo, mostrando ele ser favorável ao discurso da igualdade racial e social ou em defesa dos oprimidos. Seu discurso crítico é favorecido pelas condições que a professora da turma oferece, já que, nas aulas observadas, vemos que ela faz da sala de aula um local propício a reflexões e à produção de redes de sentido que expõem os preconceitos sociais.

No enunciado "o cara preto e pobre é sempre tratado diferente do rico e branco", chama a atenção o modo pelo qual o discurso sobre o racismo recorta e atualiza um saber vindo do interdiscurso, ${ }^{6}$ cuja memória discursiva remete à imagem do sujeito-negro como alguém que sofre demasiados preconceitos em decorrência de todo o processo histórico e social resultante da escravatura e da grande desigualdade social que ela acarretou. Isso desconstrói o imaginário de um povo sem discriminação, construído a partir da evidência da mestiçagem da população brasileira. Destacamos que, para Pêcheux (1999, p. 56), a memória configura-se como um "espaço móvel, de divisões, disjunções, de deslocamentos e de retomadas, de conflitos e de regularização [...] Um espaço de desdobramentos, réplicas, polêmicas e contra-discursos". Um espaço de produção de sentidos, portanto, que não é homogêneo, mas comporta a diferença, a ruptura com a paráfrase, ou seja, a polissemia.

Ainda sobre o texto 1, vemos, em mais de uma ocasião, a expressão do eu como sujeito do seu dizer, como em "me (grifo nosso) parece que a diferença de cor e de razões sociais são os fatores que definem constantemente os casos que serão divulgados ao público e de como a notícia será escrita”. A opção pela pessoalidade indica que o sujeito deseja manifestar como seu o ponto de vista do discurso ali materializado, diferente da impessoalidade preferida nas dissertações escolares. Isso pode revelar que esse sujeito-aluno, aliás, negro, foi particularmente afetado pela problemática abordada. Todavia, o sujeito "quebra" essa expectativa na discursividade do texto quando, no final, afirma: "acho isso complicado para aqueles que são negros". Ao proferir tal enunciado, contradiz sua posição-sujeito, pois, apesar de ser um sujeito negro, mostra não se identificar nesse texto como tal. $\mathrm{O}$ efeito da subjetividade aqui produzido é o de que o sujeito assume um discurso pessoal sobre a discriminação social, porém não se sente afetado por ela.

6 Podemos definir o interdiscurso como algo que já foi falado antes, "em outro lugar e independentemente" (PÊCHEUX, 2009, p. 149). Assim, o consideramos como o saber que torna possível todo o dizer, se constituindo como o já-dito que está na base daquilo que é passível de ser dito. 
No que se refere a gestos que indicam autoria em seu texto, podemos notar sua presença efetiva dentro da produção. Nela, temos discursivizado um saber bastante marcado pelo desejo do bemestar social que implica o fim da desigualdade e, concomitantemente, do preconceito racial. Também analisando o corpo textual, o sujeito consegue produzir sentidos por meio da textualização que produz uma progressão de ideias, certa coerência, uma vez que, em nenhum momento, ele se contradiz e, além disso, produz efeito de unidade com seu fechamento, como quando reitera, de forma clara e sucinta, seus argumentos iniciais em seu último parágrafo.

Na segunda produção dessa mesma turma, podemos perceber gestos interpretativos distintos destes primeiros. Vejamos:

\section{Texto $2^{7}$}

A visão igualitária da vida dos jornais sobre aspectos do mundo

A mídia mundial em grande parte retrata notícias de forma imparcial, ou seja, sem pender para nenhum lado da história, sejam boas ou más as informações que estão noticiando. E ela deveria se manter assim em todo diálogo com notícias, fatos e dados, mesmo que algumas vezes acabem pendendo para algum lado da história e diminuindo ou aumentando um fato ocorrido.

É óbvio que isso acontece, mas se pensarmos no grande número de noticias que saem todos os dias, acredito que perceberemos isso ser quase que irrisório, pois ainda acredito num jornalismo que tenta passar as informações verdadeiras geralmente.

Sobre isso que a notícia trata, é claro que há casos em que homens inocentes são presos, mais por conta de suas cores, religiões ou gostos, do que qualquer outra coisa. Isso na verdade é o que mais prejudica os jornais. Como noticiar uma coisa certa se o julgamento foi errado?

Iniciemos a análise discursiva do texto 2 a partir de seu título, "A visão igualitária da vida dos jornais sobre aspectos do mundo". Apesar da ambiguidade produzida pelo emprego da contração "dos" (a visão ou a vida é dos jornais?), esse enunciado configura-se como uma afirmação de que a mídia trata dos mais diversos assuntos através de uma ótica igualitária, não sendo tendenciosa em suas matérias. O discurso de defesa da imparcialidade da imprensa é materializado mais de uma vez, entretanto, para retomar a discussão da aula, abre concessões, como em "mesmo que algumas vezes acabem pendendo para algum lado da história e diminuindo ou aumentando um fato ocorrido".

Se a forma que o sujeito discursiviza acerca do mundo provém da ideologia pela qual ele é interpelado, percebemos que as FDs nas quais ele se inscreve são opostas às FDs em que se inscrevem os críticos da mídia tradicional brasileira por julgá-la identificada com o discurso classista da elite do país. Esses gestos de interpretação se tornam visíveis no decorrer de sua produção, como em: "é óbvio que isso [pender para um lado da história] acontece", em que o efeito de obviedade do discurso produz o sentido de que tais problemas são comuns, acontecem simplesmente, mas não a ponto de corromper a mídia, como sugere a adversativa: "mas se pensarmos no grande número de notícias que saem todos os dias, acredito que perceberemos isso ser quase que irrisório". Para o sujeito-enunciador desse texto, por mais que algumas notícias soem mal para certa parcela da população, isso está dentro do aceitável, uma vez que a proporção de acontecimentos noticiados do modo adequado pela grande mídia é muito maior, em suas palavras, tais fatos são "irrisórios", reforçando o sentido de que são fidedignamente retratados nas notícias.

No que se refere à forma como constitui seu discurso, é interessante observarmos que a formulação das redes de sentido presentes em sua produção se dá por meio de diversas afirmações que funcionam de modo a produzir o efeito de verdade, de que o que diz não está apenas no âmbito de sua opinião: "é óbvio", "é claro", “isso na verdade”.

7 Produção textual de aluno do terceiro ano do Ensino Médio-Técnico. 
O tema da discussão da aula, que fora o preconceito racial pela mídia, é quase ignorado no texto, cujo foco está na sua imparcialidade, sendo apenas mencionado como um erro da justiça que deve ser noticiado tal como ocorrido. Há um apagamento da população negra no texto, que aparece apenas em: "é claro que há casos em que homens inocentes são presos, mais por conta de suas cores (grifo nosso), religiões ou gostos, do que qualquer outra coisa", a questão racial é colocada ao lado de "gostos" como se fosse algo menor, uma diferença apenas. Notamos que o sujeito-enunciador não trata do racismo em si, mas somente da veracidade ou não das notícias, mesmo em casos complicados de injustiças. Além do mais, é perceptível que o caso de Rafael Braga pode ser incorporado, nesse segundo texto, à lacuna deixada pelo "isso" que se refere às excepcionalidades da imparcialidade da mídia. O fato de apagar o sujeito Rafael Braga ou mesmo a problemática do preconceito racial de sua produção textual permite-nos considerar que, para esse sujeito-aluno, esta é uma questão secundária, não sendo relevante o suficiente para ser discutida por ele, o que aproxima esse sujeito-enunciador de uma FD racista. A identificação com essa FD só foi possível de ser recuperada, nesse texto 2, porque o DPE polêmico não restringiu as interpretações possíveis, mesmo que a injúria tenha sido controlada, e, em nenhum momento, houve expressão de ódio ou enunciados discriminatórios.

Especificamente no que diz respeito a questões de autoria, temos um texto que produz efeito de unidade, que, dentro de uma linha argumentativa, possui a consistência esperada para com aquilo que se inscreve em determinada formação ideológica.

Na última produção que iremos analisar, percebemos um maior deslocamento das posições-sujeito assumidas até o momento. Ressaltamos que o seu contexto de produção também é distinto, sendo oriunda de um oitavo ano do Ensino Fundamental, de uma escola localizada na periferia do município de Bagé. Observemos:

\section{Texto $3^{8}$}

\section{O preconceito no Brasil}

Eu acho que ainda existe muito preconceito, as pessoas ainda acham que se a pessoa é negra elas têm que ser menos que eles. Não são todas as pessoas que têm preconceito, mas em muitos lugares ainda é assim e nos jornais também. Mas eles tem que botar na cabeça que a gente respira, come e sangra, como eles também fazem. Nós podemos ser negros, mas a gente tem a mesma capacidade deles, até mais!

As pessoas pensam que negro não pode ter a sua própria empresa, que nós só temos que trabalhar, mas os negros mostram cada dia mais que a gente está melhorando, e se Deus quiser, eu vou ser um desses negros que vai mostrar que nós podemos ter a mesma classe social deles.

Comecemos a análise do texto 3 por suas marcas de subjetividade. Pêcheux (2009) acredita que, a partir do momento em que se percebe o locutor propondo-se como sujeito no interior do seu discurso, ela - a subjetividade - torna-se visível. Nesse caso, percebamos sua caracterização por meio do uso recorrente do pronome pessoal "eu", como em: "eu acho que ainda existe muito preconceito" e "eu sou um desses negros". Esses gestos indicam uma proximidade do sujeito-enunciador com o discurso de reconhecimento do preconceito existente no Brasil, indicando se inscrever em FDs que se contrapõem à discriminação racial ou até mesmo se identificando com uma FD da negritude quando diz que negro tem a mesma capacidade dos brancos, ou "até mais", com exclamação.

O título de sua produção afirma, de modo breve e enfático, que a existência do preconceito no Brasil não é uma interrogação, portanto, indicaria haver um debate sobre o Brasil ter ou não uma sociedade racista. Essa questão não está em aberto, já é dada como evidência. A fim de ratificar sua afirmação, destaca-se, na sequência, "as pessoas ainda acham que se a pessoa é negra elas têm que

8 Produção textual obtida integralmente em um oitavo ano do Ensino Fundamental. 
ser menos que eles", provocando duas possíveis interpretações: (1) em que se evoca pela memória discursiva o discurso da população branca sobre os negros serem inferiores; e (2) que supõe "eles", pessoas brancas, não fazerem parte de um "nós" de que o autor participa.

Mais à frente, é retomado o discurso de que parcela da população acredita que os negros não possuem o mesmo valor que os brancos. Nisso, finalmente, temos sua posição-sujeito explicitada através do recorte "mas eles tem que botar na cabeça que a gente (grifo nosso) respira, come e sangra como eles também fazem", o que torna visível sua identificação com a raça negra, diferentemente do autor do texto 1. Esse sujeito não só percebe o racismo contra os afro-brasileiros, mas também faz parte desse grupo identitário que o sofre, tendo em vista que, ao inserir-se em "a gente", marca mais uma vez sua subjetividade e se coloca como membro dessa comunidade. Essa marca também nos permite perceber que há uma distinção entre um "nós" ou "a gente" e um "eles", construindo o efeito de oposição entre dois "sujeitos coletivos" distintos. Essas significações polarizadas indicam que, para o autor do texto 3, existe um embate entre um "nós", ao qual ele pertence, e um "eles", indicando a tensão entre negros e brancos que é calcificada nos meandros de nossa sociedade.

Aqui é o debate sobre a mídia que fica em segundo plano, aparecendo somente uma vez ao afirmar: "não são todas as pessoas que têm preconceito, mas em muitos lugares ainda é assim e nos jornais (grifo nosso) também”. Os jornais são mencionados apenas para dar ênfase ao preconceito existente no Brasil. A questão da parcialidade ou imparcialidade da mídia perde espaço nesse texto para o preconceito racial que estrutura a sociedade brasileira.

Palavras como "come" e "sangra" em: "mas eles tem que botar na cabeça que a gente respira, come e sangra (grifos nosso)", seguidas dos enunciados "nós podemos ser negros, mas a gente tem a mesma capacidade deles, até mais!" e "as pessoas pensam que negro não pode ter a sua própria empresa, que nós só temos que trabalhar”, indicam, além da raça, o pertencimento a uma classe social baixa, uma vez que é visível também o desejo de ascensão social, como se o negro pobre tivesse que subir na escala econômica para ser respeitado. Tal discurso provém de uma formação ideológica capitalista, em que se pressupõe um ideal de conquista em que todos podem "conseguir ascender" na vida por seus próprios méritos, e, no caso do negro, demonstrar isso é provar o seu valor. Pois não basta provar que o negro "come" e "sangra" como o branco, isso os animais também fazem, é preciso ser um empresário que representa a figura do patrão em oposição ao trabalhador que a ele é subordinado. Em todo o texto, há a produção do sentido de que a desigualdade é latente em nossa sociedade, apresenta consistência, portanto, mesmo com a periferia em que a escola está situada.

É interessante notar a maneira como a composição desse texto torna visível a aparição de um sujeito-autor de seus dizeres a partir de seus gestos singulares de interpretação. Diferentemente do que ocorre nas duas primeiras produções, aqui o sujeito-enunciador não só repete dizeres do interdiscurso, mas também produz novos enunciados a partir das marcas de subjetividade. Ao se colocar ativamente dentro do texto, materializa um discurso de resistência contra uma FD racista, afirmando a capacidade do sujeito-negro e a sua própria.

Orlandi (2008) sugere que, para a "efetivação" da função-autor, os sujeitos-enunciadores precisam organizar os discursos no texto de modo a produzir um efeito de unidade e fechamento. Partindo dessa afirmação, destacamos tais especificidades aparecerem nas produções analisadas, trazendo com elas discursos afetados, de distintas maneiras, pela responsabilidade de um dizer social. Afinal, o sujeito só se faz autor se o que ele produz conseguir ser interpretável (ORLANDI, 2008), e, nesses casos, fica visível que suas significações são. Porém, destacamos a última produção como a que revelou maior grau de autoria, sendo que, além de defender um ponto de vista, o autor se inscreve no texto de modo a dar maior relevância ao tema e consistência aos seus argumentos. 


\section{Considerações finais}

A análise discursiva dos textos produzidos por alunos das escolas públicas em que atuamos nos proporcionou algumas reflexões. Se, por um lado, observamos claramente gestos interpretativos bastante distintos, por outro, notamos um ponto de congruência entre eles: o desenvolvimento da autoria, quando o sujeito produz o efeito de originalidade e autenticidade em seu texto, rompendo com meras repetições de dizeres, provocando, assim, deslocamentos de sentidos em suas produções, o que o coloca em uma posição de autor.

Mais do que apenas uma tipologia discursiva, o DPE polêmico aparece como um aliado do professor para o desenvolvimento de alunos que consigam ser autores dos seus próprios dizeres, pois, nessa perspectiva, cria-se uma relação em que estes passam de uma posição de somente ouvintes ou repetidores para uma em que possam discursivizar suas visões sobre o mundo.

Finalmente, percebamos que trabalhar, de forma mais enfática, temáticas socioculturais ou transversais que dialogam com a formação de um sujeito-cidadão é de fundamental importância para o desenvolvimento de uma sociedade democrática. Afinal, um sujeito pensante, capaz de refletir sobre as problemáticas à sua volta e produzir sentidos historicizados para o que lê/vê ou ouve, torna-se cada vez mais necessário em uma era em que o discurso rompe as barreiras do espaço/tempo nas redes virtuais.

\section{Referências}

ALTHUSSER, L. Aparelhos ideológicos de Estado: nota sobre os aparelhos ideológicos de estado (AIE). 6. ed. Tradução Walter José Evangelista e Maria Laura Viveiros de Castro. Rio de Janeiro: Graal, 1992.

ASSOLINI, F. E. P. Interpretação e letramento no Ensino Fundamental: dificuldades e perspectivas para a prática pedagógica escolar. In: TFOUNI, Leda V. (org.). Letramento, escrita e leitura. Campinas, SP: Mercado de Letras, 2011. p. 143-162.

ASSOLINI, F. E. P. O discurso lúdico na sala de aula: letramento, autoria e subjetividade. In: ASSOLINI, F. E. P.; LASTÓRIA, A. C. (org.). Diferentes linguagens no contexto escolar: questões conceituais e apontamentos metodológicos. Florianópolis: Editora Insular, 2013. p. 33-52.

BRASIL. Base nacional comum curricular. Brasília, DF: SEB/MEC, 2018. Disponível em: <file://D:/UNIPAMPA/Graduação\%20-\%20Unipampa/textos\%20teóricos\%20e\%20oficiais/ BNCC_19dez2018_site.pdf $>$. Acesso em: 10 jan. 2019.

BRASIL. Secretaria de Educação Fundamental. Parâmetros curriculares nacionais. Brasília, DF: MEC/SEF, 1998.

FERNANDES, C. O visível e o invisível da imagem: uma análise discursiva da leitura e da escrita de livros de imagens. Campinas, SP: Mercado de Letras, 2017.

FOUCAULT, M. O que é um autor? 3. ed. Lisboa: Vega, 1992.

FUCHS, C.; PÊCHEUX, M. Por uma análise automática do discurso; atualização e perspectivas. In: GADET, F.; HAK, T. (org.). Análise do discurso: uma introdução à obra de Michel Pêcheux. 3. ed. Campinas, SP: Editora da UNICAMP, 1997. p.163-187.

ORLANDI, E. P. Análise de discurso: princípios \& procedimentos. São Paulo: Pontes, 2002.

ORLANDI, E. P. Interpretação, autoria, leitura e efeitos do simbólico. Campinas, SP: Pontes, 2007. 
ORLANDI, E. P. Discurso e leitura. 8. ed. São Paulo: Cortez, 2008.

ORLANDI, E. P. A linguagem e seu funcionamento: as formas do discurso. 5. ed. Campinas, SP: Pontes, 2009.

PÊCHEUX, M. Por uma análise automática do discurso. In: GADET, F.; HAK, T. (Org.). Análise do discurso: uma introdução à obra de Michel Pêcheux. 3. ed. Campinas, SP: Editora da UNICAMP, 1997. p. 61-89.

PÊCHEUX, M. Papel da memória. In: ACHARD, Pierre et al. (org.). Papel da memória. São Paulo: Pontes, 1999. p. 49-57.

PÊCHEUX, M. Semântica e discurso: uma crítica à afirmação do óbvio. 4. ed. Campinas, SP: Editora da UNICAMP, 2009. 
